\title{
Mass Spectra of the Deuteromethanes
}

\author{
By Vernon H. Dibeler and Fred L. Mohler
}

\begin{abstract}
The four deuteromethanes have been synthesized and their mass spectra obtained with a Consolidated mass spectrometer. The sensitivities of the molecule ions of $\mathrm{CH}_{4}$ and of $\mathrm{CD}_{4}$ are equal within the estimated uncertainty. The total ionization is the same for $\mathrm{CH}_{4}, \mathrm{CH}_{3} \mathrm{D}$, and $\mathrm{CH}_{2} \mathrm{D}_{2}$ but is significantly low for $\mathrm{CD}_{4}$. The mass spectra of the deuteromethanes are not predictable from $\mathrm{CH}_{4}$ by statistical considerations alone. In agreement with previously published data on $\mathrm{CH}_{3} \mathrm{D}$, probability factors of 1.18 and 0.45 were observed for the dissociation of an $\mathrm{H}$ atom or a $\mathrm{D}$ atom compared with the dissociation of an $\mathrm{H}$ atom from $\mathrm{CH}_{4}$. Whereas these factors remain approximately constant for subsequent dissociations in the same molecule, they differ markedly for the three protiodeuteromethanes. Wide divergence is observed for some probability factors obtained in dissociations of two or more atoms.
\end{abstract}

\section{Introduction}

The use of deuterium and deuterated molecules in tracer experiments has given much information on reaction mechanisms, kinetics, and catalysis. One of the most rewarding methods of observing isotope exchanges and analyzing the raction products of tracer experiments is that of mass spectroscopy. In all but the simplest experiments, however, this method requires calibration patterns of the substances encountered in the investigation, and it is obvious that eventually a complete catalog of mass spectra of deuterated and other isotopic molecules will be required. In addition to their practical value, mass spectra of isotopic molecules are of considerable theorectical interest. Studies of a few simple deuterated hydrocarbons have been reported by Delfosse and Hipple [1], ${ }^{1}$ Evans, Bauer, and Beach [2], Mohler and Dibeler [3], and Turkevich, Friedman, Solomon, and Wrightson [4]. These studies indicate that although the sensitivity (ion current per unit of pressure) of the molecule ion and the total ion current for all dissociation processes is the same for isotopic molecules, the effect of deuterium substitution on the relative probabilities of the various dissociation processes is not predictable from statistical considerations alone. Appropriate corrections must be made for differences in dissociation probability of $\mathrm{C}-\mathrm{H}$ and $\mathrm{C}-\mathrm{D}$ bonds, as well as the difference in behavior of $\mathrm{H}$ atoms in normal hydrocarbons and $\mathrm{H}$ atoms in deuterohydrocarbons.

Although information has been published on the Raman [5] and infrared [6] spectra of all of the deuteromethanes, mass spectra of only $\mathrm{CH}_{3} \mathrm{D}[2,4]$ and $\mathrm{CD}_{4}[4]$, and a partial spectrum of $\mathrm{CHD}_{3}[4]$ have been reported. Aecordingly, we report the complete mass spectra of all of the deuteromethanes to extend the published data on this group of molecules. Also, we wish to reexamine the statistical relationship of $\mathrm{CH}_{4}$ to the deuteromethanes for the complete series now available.

\section{Experimental Details}

The mass spectra were obtained with a Consolidated mass spectrometer by using conventional techniques. The energy of the ionizing electrons

\footnotetext{
I Figures in brackets indicate the literature references at the end of this paper
}

was nominally $50 \mathrm{v}$. The temperature of the ionization chamber was about $245^{\circ} \mathrm{C}$. Possible traces of hydrogen were pumped off of all samples at liquid hydrogen temperature, and the sample storage bulbs were cooled to liquid nitrogen temperature before samples were admitted to the mass spectrometer. The pressure of the sample in the inlet reservoir was measured with a diaphragm-type micromanometer [7].

Methane was "research grade" material obtained from Phillips Petroleum Co. and used without further purification. The purity, as stated by the manufacturer, was 99.7 mole percent. The most probable impurities were nitrogen, ethane, and carbon dioxide.

Mono-, di-, and trideuteromethane were prepared by the reaction of lithium aluminum deuteride on the appropriate bromo-methane, according to the method of Finholt, Bond, and Schlesinger [8]. The apparatus and techniques were similar to those previously used in the reduction of halomethanes with lithium aluminum hydride [9].

In addition to the methanes, small amounts of heavier hydrocarbons and hydrogen were observed in the products. These were effectively removed as described above before the sample was admitted to the mass spectrometer. As the attainment of high isotopic purity became more difficult with increasing numbers of $\mathrm{D}$ atoms in the molecule, no attempt was made to prepare tetradeuteromethane by this method. The $\mathrm{CD}_{4}$ was very kindly given by Leo $\mathrm{A}$. Wall. It was prepared by the reduction of carbon dioxide with deuterium over a supported nickel catalyst. The product contained 1.8 mole percent of $\mathrm{CHD}_{3}$. Hydrocarbons heavier than $\mathrm{CD}_{4}$ were not detected by the mass spectrometer.

The observed sensitivity of $\mathrm{CH}_{4}(31.2 \mathrm{div} /$ micron $)$ and of $\mathrm{CD}_{4}$ (31.9 div/micron) were considered equal within the estimated experimental uncertainty. The average value (31.5) was assumed for the sensitivities of $\mathrm{CH}_{3} \mathrm{D}, \mathrm{CH}_{2} \mathrm{D}_{2}$, and $\mathrm{CHD}_{3}$, and on this basis the mass spectra of the deuteromethanes were corrected for isotopic impurities. After correcting the mass spectrum of " $\mathrm{CH}_{3} \mathrm{D}$ " for the contribution of ions containing carbon-13, a residual peak on mass 18 above the normal $\mathrm{H}_{2} \mathrm{O}$ background indicated the presence of 1 percent of $\mathrm{CH}_{2} \mathrm{D}_{2}$. The sum of the partial pressures of $\mathrm{CH}_{3} \mathrm{D}$ and $\mathrm{CH}_{2} \mathrm{D}_{2}$ (obtained from the mass 17 and 18 peak heights and the sensitivities) 
subtracted from the total sample pressure indicated 1 percent of $\mathrm{CH}_{4}$ also present. An exact correction of the mass spectrum was made for the latter, and an approximate correction was made for the $\mathrm{CH}_{2} \mathrm{D}_{2}$.

Similarly, the mass spectrum of the sample of dideuteromethane showed a trace of $\mathrm{CHD}_{3}$. The total partial pressures of the $\mathrm{CHD}_{3}$ and $\mathrm{CH}_{2} \mathrm{D}_{2}$ subtracted from the sample pressure indicated the presence of 10 percent of $\mathrm{CH}_{3} \mathrm{D}$ plus $\mathrm{CH}_{4}$. Approximate corrections were made to the mass spectrum assuming the amount of $\mathrm{CH}_{4}$ to be negligible.

The isotopic purity of the trideuteromethane was the least satisfactory of the group. The product obtained from the reaction of lithium aluminum deuteride with bromoform was only 60 percent of $\mathrm{CHD}_{3}$. The partial pressures of the $\mathrm{CD}_{4}$ impurity (obvious from the mass spectrum) and the $\mathrm{CHD}_{3}$ subtracted from the total pressure gave a partial pressure assumed to be $\mathrm{CH}_{2} \mathrm{D}_{2}$. The corrected mass spectrum was in good agreement with the spectrum derived from a second sample of $\mathrm{CD}_{4}$ obtained from Wall, containing 30 percent of $\mathrm{CHD}_{3}$. This sample contained only a small amount of $\mathrm{CH}_{2} \mathrm{D}_{2}$, as indicated by the partial pressure computations. Finally, the mass spectra summarized in the following section were obtained by successive approximations, as indicated above. With the possible exception of $\mathrm{CHD}_{3}$, this process should give satisfactory results. Fortunately, $\mathrm{CHD}_{3}$ was not an appreciable impurity in any of the preparations. The estimated uncertainty in the principal ions of the spectra of $\mathrm{CH}_{4}, \mathrm{CH}_{3} \mathrm{D}$, and $\mathrm{CD}_{4}$ is about 1 percent. It is probably somewhat higher for $\mathrm{CH}_{2} \mathrm{D}_{2}$ and is estimated as 5 percent for $\mathrm{CHD}_{3}$.

\section{Results}

The relative ion intensities obtained for methane, and the four deuteromethanes are given in Table 1. Correction has been made for ions containing carbon-13. The sum of the carbon-group ions for each molecule is given near the bottom of the appropriate column. The measured sensitivity (molecule-ion current per unit of pressure) is also given for $\mathrm{CH}_{4}$ and $\mathrm{CD}_{4}$. No doubly charged ions were observed. One ion due to a metastable transition was observed in the spectrum of $\mathrm{CD}_{4}$. This ion observed at $m / e=16.2$ was only 0.05 percent of the abundance of the molecule ion and was attributed to the delayed dissociation $\mathrm{CD}_{4}{ }^{+} \rightarrow \mathrm{CD}_{3}{ }^{+}+$D. No independent check on the isotopic composition of the methanes was employed. However, the mass spectrum of $\mathrm{CH}_{3} \mathrm{D}$ is in excellent agreement with previously published data from two different laboratories $[2,4]$. Also, the mass spectrum of $\mathrm{CD}_{4}$ and the odd-mass ions of $\mathrm{CHD}_{3}$ are in good agreement with the spectrum of $\mathrm{CD}_{4}$ and the partial spectrum of $\mathrm{CHD}_{3}$ previously reported by Turkevich et al. [4].

In the dissociation patterns of $\mathrm{CH}_{3} \mathrm{D}$ and $\mathrm{CH}_{2} \mathrm{D}_{2}$, some of the mass peaks come from two different ions; for example, mass 14 is $\mathrm{CH}_{2}{ }^{+}$and $\mathrm{CD}^{+}$. In order to obtain information on the relative probabilities of dissociating $\mathrm{H}$ atoms and $\mathrm{D}$ atoms from various isotopic configurations, some assumption
TABLE 1. Mass spectra of methane and the deuteromethanes for 50-v electrons

\begin{tabular}{|c|c|c|c|c|c|}
\hline$m / e$ & $\mathrm{CH}_{4}$ & $\mathrm{CH}_{3} \mathrm{D}$ & $\mathrm{CH}_{2} \mathrm{D}_{2}$ & $\mathrm{CHD}_{3}$ & $\mathrm{CD}_{4}$ \\
\hline 1. & 7.05 & 5.92 & 4.40 & 2.05 & \\
\hline 2 & 0.34 & 0.68 & 1. 24 & 1.86 & 3.00 \\
\hline $3 \ldots$ & -.... & .11 & 0.18 & 0.11 & \\
\hline $4 \ldots$ & - n & (n.... & .04 & .09 & 0.22 \\
\hline 12. & 2. 57 & 2.46 & 2. 39 & 2. 30 & 2.19 \\
\hline $13 \ldots$ & 8.21 & 4.90 & 2.80 & 1. 42 & \\
\hline $14 \ldots$ & 16.3 & 8.80 & 6.39 & 6.41 & 7. 23 \\
\hline $15 \ldots$ & 86.1 & 20.9 & 9.79 & 6.75 & \\
\hline 16. & 100.0 & 77.2 & 30.7 & 13.2 & 12.5 \\
\hline 17 & ...... & 100.0 & 62.4 & 51.1 & \\
\hline $18 \ldots \ldots \ldots$ & -.... & -.... & 100.0 & 27.7 & 83.0 \\
\hline $\begin{array}{l}19 \\
20\end{array}$ & (n...... & (n) & (n.... & 100.0 & 100.0 \\
\hline Total C-group ions_... & 213.2 & 214.3 & 214.5 & 208.9 & 204.9 \\
\hline Sensitivity ...... & 31.2 & ...... & -..... & ...... & 31.9 \\
\hline
\end{tabular}

must be made to derive the relative amounts of each contributing ion obtained in the dissociation processes. In the case of $\mathrm{CHD}_{3}$, this problem does not arise, as each peak comes from a single type of ion. It is unfortunate that experimental errors are greatest in this spectrum. In the computations for $\mathrm{CH}_{3} \mathrm{D}$ and $\mathrm{CH}_{2} \mathrm{D}_{2}$, it will be assumed that the probability of removing one atom (either $\mathrm{H}$ or $\mathrm{D}$ ) is equal to the probability of removing one $\mathrm{H}$ from $\mathrm{CH}_{4}$; the probability of removing two atoms is equal to that of removing two $\mathrm{H}$ atoms from $\mathrm{CH}_{4}$, and so forth. This assumption is consistent with the fact that the sums of the ions in $\mathrm{CH}_{4}, \mathrm{CH}_{3} \mathrm{D}$, and $\mathrm{CH}_{2} \mathrm{D}_{2}$ are nearly equal, as shown in the following computations. Starting from the low-mass end of the $\mathrm{CH}_{3} \mathrm{D}$ spectrum, the contribution of each type of ion is computed in the following manner: Mass 13 results from $\mathrm{CH}^{+}$only and is equal to 4.90 (table 1 ). $\mathrm{As} \mathrm{CH}^{+}$ and $\mathrm{CD}^{+}$are both formed by the dissociation of three atoms, the above assumption permits us to calculate the $\mathrm{CD}^{+}$abundance as the difference: $\mathrm{CH}^{+}$ in $\mathrm{CH}_{4}(8.21)$ minus $\mathrm{CH}^{+}$in $\mathrm{CH}_{3} \mathrm{D}(4.90)$ equals 3.31. Further, the total abundance of ions of mass 14 in $\mathrm{CH}_{3} \mathrm{D}$ is 8.80 ; consequently, the $\mathrm{CH}_{2}{ }^{+}$abundance is given by $8.80-3.31=5.49$. Continuing in this manner, one computes the abundance of $\mathrm{CH}_{2} \mathrm{D}^{+}$ as 76.0 instead of the observed value 77.2. There is a residual error, because the sum of masses 13,14 , and 15 in $\mathrm{CH}_{4}$ is not exactly equal to the sum of masses 13 to 16 in $\mathrm{CH}_{3} \mathrm{D}$. If the values for $\mathrm{CH}_{4}$ are multiplied by 1.01, the sums are exactly equal, and no residual error occurs. This device merely distributes any error in the experimental data or in the assumptions. Similarly, for $\mathrm{CH}_{2} \mathrm{D}_{2}$ a factor of 1.013 eliminates the residual error. In this manner the ion abundances listed in table 2 were derived.

There are included in table 2 , the a priori probabilities of removing $\mathrm{H}$ or $\mathrm{D}$ atoms from the three molecules to give the various ions. The abundances of the various ions are not in the ratios of the a priori probabilities. In $\mathrm{CH}_{3} \mathrm{D}$, for example, the observed abundance of the $\mathrm{CH}_{2} \mathrm{D}^{+}$ion is not $3 / 4 \times 87.0=65.2$, but 1.183 times $65.2(77.2)$, where 87.0 is the corrected abundance of $\mathrm{CH}_{3}^{+}$in $\mathrm{CH}_{4}$. On the other hand, the $\mathrm{CH}_{3}^{+}$ion in $\mathrm{CH}_{3} \mathrm{D}$ is $0.45 \times \frac{1}{4} \times 87.0=9.8$. The factors 1.18 and 0.45 are a measure of the prob- 
TABLE 2. Computed ion abundance in isotopic methanes

\begin{tabular}{|c|c|c|c|c|c|c|c|c|}
\hline \multicolumn{3}{|c|}{$\mathrm{CH}_{3} \mathrm{D}$} & \multicolumn{3}{|c|}{$\mathrm{CH}_{2} \mathrm{D}_{2}$} & \multicolumn{3}{|c|}{$\mathrm{CHD}_{3}$} \\
\hline Ion & $\begin{array}{l}\text { A bun- } \\
\text { dance }\end{array}$ & $\begin{array}{c}\text { A pri- } \\
\text { ori } \\
\text { proba- } \\
\text { bility }\end{array}$ & Ion & $\begin{array}{l}\text { Abun- } \\
\text { dance }\end{array}$ & $\begin{array}{l}\text { A pri- } \\
\text { ori } \\
\text { proba- } \\
\text { bility }\end{array}$ & Ion & $\begin{array}{l}\text { Abun- } \\
\text { dance }\end{array}$ & $\begin{array}{l}\text { A pri- } \\
\text { ori } \\
\text { proba- } \\
\text { bility }\end{array}$ \\
\hline $\begin{array}{l}\mathrm{CH}_{2} \mathrm{D} \\
\mathrm{CH}_{3} \\
\mathrm{CHD} \mathrm{CH}_{2} \mathrm{CH}_{3} \\
\mathrm{CD} \\
\mathrm{CH}\end{array}$ & $\begin{array}{c}77.2 \\
9.8 \\
11.1 \\
5.40 \\
3.40 \\
4.90\end{array}$ & $\begin{array}{l}3 / 4 \\
1 / 4 \\
1 / 2 \\
1 / 2 \\
1 / 4 \\
3 / 4\end{array}$ & $\begin{array}{l}\mathrm{CHD}_{2} \\
\mathrm{CH}_{2} \mathrm{D} \\
\mathrm{CD}_{2} \\
\mathrm{CHD} \mathrm{CH}_{2} \\
\mathrm{CD} \\
\mathrm{CH}\end{array}$ & $\begin{array}{c}62.4 \\
24.9 \\
5.84 \\
9.79 \\
0.87 \\
5.52 \\
2.80\end{array}$ & $\begin{array}{l}1 / 2 \\
1 / 2 \\
136 \\
2 / 3 \\
116 \\
1 / 2 \\
1 / 2\end{array}$ & $\begin{array}{l}\mathrm{CD}_{3} \\
\mathrm{CHD}_{2} \\
\mathrm{CD}_{2} \\
\mathrm{CHD} \\
\mathrm{CD} \\
\mathrm{CH}\end{array}$ & $\begin{array}{c}27.7 \\
51.1 \\
13.2 \\
6.75 \\
6.41 \\
1.42\end{array}$ & $\begin{array}{l}1 / 4 \\
3 / 4 \\
1 / 2 \\
1 / 2 \\
3 / 4 \\
1 / 4\end{array}$ \\
\hline
\end{tabular}

ability of dissociating an $\mathrm{H}$ atom or a $\mathrm{D}$ atom from $\mathrm{CH}_{3} \mathrm{D}$ compared with the dissociation of an $\mathrm{H}$ atom from $\mathrm{CH}_{4}$. These probability factors are denoted by the symbols $\mathrm{H}\left(\mathrm{H}_{3} \mathrm{D}\right)$ and $\mathrm{D}\left(\mathrm{H}_{3} \mathrm{D}\right)$ in table 3 . The letter outside the parenthesis indicates the atom dissociated, while the letters inside the parenthesis indicate the configuration before the dissociation, the presence of a carbon atom being understood. One can similarly compute $\mathrm{H}\left(\mathrm{H}_{2} \mathrm{D}_{2}\right)$ and $\mathrm{D}\left(\mathrm{H}_{2} \mathrm{D}_{2}\right)$. In $\mathrm{CHD}_{3}$, one uses the observed sum of $\mathrm{CD}_{3}^{+}$and $\mathrm{CHD}_{2}^{+}$without reference to $\mathrm{CH}_{4}$ to compute the corresponding factors $\mathrm{H}\left(\mathrm{HD}_{3}\right)$ and $\mathrm{D}\left(\mathrm{HD}_{3}\right)$.

Removal of two $\mathrm{H}$ atoms from $\mathrm{CH}_{3} \mathrm{D}$ has an $a$ priori probability of one-half compared with $\mathrm{CH}_{4}$, and the probability factor can be expressed as the product of the probabilities $\mathrm{H}\left(\mathrm{H}_{3} \mathrm{D}\right)$ and $\mathrm{H}\left(\mathrm{H}_{2} \mathrm{D}\right)$. There is an assumption involved in expressing the probability of removing several atoms as the product of the independent probabilities, and it is of interest to see if the assumption leads to consistent results. There are two ways of removing $\mathrm{H}+\mathrm{D}$ atoms from these molecules; removing $\mathrm{H}$ first or removing $\mathrm{D}$ first. For $\mathrm{CH}_{3} \mathrm{D}$, the probability for the observed $\mathrm{CH}_{2}^{+}$ compared with the a priori value can be expressed as:

$$
\begin{aligned}
\frac{\mathrm{CH}_{2}^{+} \text {from } \mathrm{CH}_{3} \mathrm{D}}{\mathrm{CH}_{2}^{+} \text {from } \mathrm{CH}_{4}}= & 1 / 4 \times \mathrm{H}\left(\mathrm{H}_{3} \mathrm{D}\right) \times \\
& \mathrm{D}\left(\mathrm{H}_{2} \mathrm{D}\right)+1 / 4 \times \mathrm{D}\left(\mathrm{H}_{3} \mathrm{D}\right) .
\end{aligned}
$$

All terms are known except $\mathrm{D}\left(\mathrm{H}_{2} \mathrm{D}\right)$, which can be computed from the above. There are three ways of removing $2 \mathrm{H}+\mathrm{D}$ atoms to give $\mathrm{CH}^{+}$, and all constants are known except D(HD), which can be derived in a manner similar to the above.

TABLE 3. Probabilities of dissociating $\mathrm{H}$ or $\mathrm{D}$ atoms from

\begin{tabular}{|c|c|c|}
\hline $\mathrm{CH}_{3} \mathrm{D}$ & $\mathrm{CH}_{2} \mathrm{D}_{2}$ & $\mathrm{CHD}_{3}$ \\
\hline $\begin{array}{l}\mathrm{H}\left(\mathrm{H}_{3} \mathrm{D}\right)=1.18 \\
\mathrm{D}\left(\mathrm{H}_{3} \mathrm{D}\right)=0.45 \\
\mathrm{H}\left(\mathrm{H}_{2} \mathrm{D}\right)=1.14 \\
\mathrm{H}\left(\mathrm{HD}^{\mathrm{D}}=1.21\right. \\
\mathrm{D}\left(\mathrm{H}_{2} \mathrm{D}\right)=0.73 \\
\mathrm{D}(\mathrm{HD})=.78\end{array}$ & $\begin{aligned} \mathrm{H}\left(\mathrm{H}_{2} \mathrm{D}_{2}\right) & =1.43 \\
\mathrm{D}\left(\mathrm{H}_{2} \mathrm{D}_{2}\right) & =0.57 \\
\mathrm{H}\left(\mathrm{HD}_{2}\right) & =1.49 \\
\left(\mathrm{D}\left(\mathrm{H}_{2} \mathrm{D}\right)\right. & =0.54) \\
\mathrm{a} \mathrm{H}\left(\mathrm{H}_{2} \mathrm{D}\right) & =1.16 \\
\mathrm{~b} \mathrm{D}\left(\mathrm{HD} \mathrm{D}_{2}\right) & =0.79 \\
(\mathrm{H}(\mathrm{HD}) & =1.05) \\
(\mathrm{D}(\mathrm{HD}) & =0.90)\end{aligned}$ & $\begin{array}{l}\mathrm{H}\left(\mathrm{HD}_{3}\right)=1.41 \\
\mathrm{D}\left(\mathrm{HD}_{3}=0.87\right. \\
\mathrm{D}\left(\mathrm{HD}_{2}\right)=.78 \\
\left(\mathrm{D}\left(\mathrm{HD}_{2}=1.07\right)\right. \\
\mathrm{H}\left(\mathrm{HD}_{2}\right)=1.43 \\
(\mathrm{H}(\mathrm{HD})=0.95)\end{array}$ \\
\hline
\end{tabular}
deuteromethane ions

a Derived by using value of $\mathrm{D}\left(\mathrm{HD}_{2}\right)$ from $\mathrm{CHD}_{3}$ spectrum.

b Derived by using $\mathrm{H}\left(\mathrm{H}_{2} \mathrm{D}\right)$ from $\mathrm{CH}_{3} \mathrm{D}$ spectrum.
Computations for the dissociation of $\mathrm{CHD}_{3}$ can be carried out in the same manner by using only the data from the $\mathrm{CHD}_{3}$ spectrum. In $\mathrm{CH}_{2} \mathrm{D}_{2}$ more constants are involved, and data from $\mathrm{CHD}_{3}$ or $\mathrm{CH}_{3} \mathrm{D}$ must be used to derive one of the constants.

\section{Discussion}

The constants derived from the three spectra are not entirely consistent. It should be noted that errors are necessarily cumulative in computing probabilities of removing successive atoms from the methanes, consequently computational errors are greatly magnified. $\mathrm{H}\left(\mathrm{H}_{2} \mathrm{D}\right)$ can be derived either from $\mathrm{CH}_{3} \mathrm{D}$ or $\mathrm{CH}_{2} \mathrm{D}_{2}$, but in the latter case the value of $\mathrm{D}\left(\mathrm{HD}_{2}\right)$ from $\mathrm{CHD}_{3}$ must be used. The pairs of values derived for $\mathrm{H}\left(\mathrm{H}_{2} \mathrm{D}\right)$ or for $\mathrm{D}\left(\mathrm{HD}_{2}\right)$ are entirely consistent in the three spectra. Values for $\mathrm{H}\left(\mathrm{HD}_{2}\right)$ from $\mathrm{CH}_{2} \mathrm{D}_{2}$ and $\mathrm{CHD}_{3}$ are equal within experimental error. Other values do not check well. The values for $\mathrm{D}\left(\mathrm{H}_{2} \mathrm{D}\right)$ are 0.73 from $\mathrm{CH}_{3} \mathrm{D}$ and 0.54 from $\mathrm{CH}_{2} \mathrm{D}_{2}$. The former is probably more reliable, as the $\mathrm{CH}_{2}^{+}$ion in $\mathrm{CH}_{2} \mathrm{D}_{2}$ (table 2) is very small and any uncertainty in computing table 2 makes more uncertain the value derived from $\mathrm{CH}_{2} \mathrm{D}_{2}$. Values for $\mathrm{H}(\mathrm{HD})$ and $\mathrm{D}(\mathrm{HD})$ can be derived from all three spectra, and the values are quite divergent. Computations involve products of three probabilities, and thus errors are magnified. The values derived from the $\mathrm{CHD}_{3}$ spectrum, D $(\mathrm{HD})=1.07$ and $\mathrm{H}(\mathrm{HD})=.95$, are definitely contrary to expectations, as it seems to be quite generally true that the probability of removing $\mathrm{H}$ from a radical containing D is greater than 1, and the probability of removing $\mathrm{D}$ from a radical containing $\mathrm{H}$ is less than 1 . In table 3 values that are considered less reliable are inclosed in parentheses.

It is concluded that the assumptions used to derive the probability constants are at least approximately true. The inconsistencies shown in table 3 are no greater than are to be expected if there are experimental uncertainties amounting to several percent of the maximum peak, and this is very likely true in the $\mathrm{CH}_{2} \mathrm{D}_{2}$ and $\mathrm{CHD}_{3}$ spectra.

In criticism it can be said that it is probably not accurately true that the probability of removing one, two, or three atoms from these molecules is equal to the probability in $\mathrm{CH}_{4}$. If one uses $\mathrm{CD}_{4}$ as the basis of comparison, somewhat different values are derived. There is also reason to doubt whether the probability of removing two or three atoms is accurately equal to the product of the probabilities of removing single atoms, for appearance potential measurements show that $\mathrm{H}$ atoms can be removed in pairs to give $\mathrm{H}_{2}$ and not 2H. However, L. G. Smith has shown [10] that most ions in methane are formed by the dissociation of $\mathrm{H}$ atoms. In any event, the assumption seems to be approximately true, and without this assumption there is little possibility of extending data on probability constants observed in one molecule to another. It has been pointed out by E. J. Wells that there are enough interrelations between constants to derive all the constants without the 
assumptions that probabilities of removing atoms are equal to those found in methane. Unfortunately, one must base such a derivation on the values derived from $\mathrm{CHD}_{3}$ that are considered least reliable experimentally.

\section{Conclusions}

The sensitivities of $\mathrm{CH}_{4}$ and $\mathrm{CD}_{4}$ differ by about 2 percent and are probably equal within the experimental uncertainty. The total ionization is apparently the same for $\mathrm{CH}_{4}, \mathrm{CH}_{3} \mathrm{D}$, and $\mathrm{CH}_{2} \mathrm{D}_{2}$. The low value for $\mathrm{CHD}_{3}$ is not significant in view of the uncertainty in this spectrum. The difference in the total ionization of $\mathrm{CH}_{4}$ and $\mathrm{CD}_{4}$, however, is greater than the estimated error; and since the number of dissociation processes remains the same, the difference is probably a result of the lower probability of dissociating $\mathrm{C}-\mathrm{D}$ bonds.

Although our experimental results for $\mathrm{CH}_{3} \mathrm{D}$ are in good agreement with Turkevich et al. and with Evans, Bauer, and Beach, the different authors have used somewhat different assumptions in the interpretation of results. Although the assumptions used by
Evans, Bauer, and Beach lead to nearly the same results in $\mathrm{CH}_{3} \mathrm{D}$, their assumptions did not seem to be generally applicable to the three spectra $\mathrm{CH}_{3} \mathrm{D}$, $\mathrm{CH}_{2} \mathrm{D}_{2}$, and $\mathrm{CHD}_{3}$, necessitating the different approach used in this work.

\section{References}

[1] J. Delfosse and J. A. Hipple, Phys. Rev. 54, 1060 (1938). [2] M. W. Evans, N. Bauer, and J. Y. Beach, J. Chem. Phys. 14, 701 (1946).

[3] F. L. Mohler and V. H. Dibeler, Phys. Rev. 72, 158A (1947).

[4] J. Turkevich, L. Friedman, E. Solomon, and F. M. Wrightson, J. Am. Chem. Soc. 70, 2638 (1948).

[5] G. E. MacWood and H. C. Urey, J. Chem. Phys. 4, 402 (1936).

[6] W. S. Benedict, K. Morikawa, R. B. Barnes, and H. S. Taylor, J. Chem. Phys. 5, 1 (1937).

[7] V. H. Dibeler and F. Cordero, J. Research NBS, publication pending.

[8] A. E. Finholt, A. C. Bond, Jr., and H. I. Schlesinger, J. Am. Chem. Soc. 69, 1199 (1947).

[9] V. H. Dibeler, J. Research NBS 44, 363 (1950) RP2083.

[10] L. G. Smith, Phys. Rev. 51, 263 (1937).

Washington, May 5, 1950

\title{
First Dissociation Constant of Succinic Acid from $0^{\circ}$ to $50^{\circ} \mathrm{C}$ and Related Thermodynamic Quantities
}

\author{
By Gladys D. Pinching and Roger G. Bates
}

\begin{abstract}
The first dissociation constant, $K_{1}$, of succinic acid was determined at intervals of 5 degrees from $0^{\circ}$ to $50^{\circ} \mathrm{C}$ from measurements of the electromotive force between hydrogen and silver-silver-chloride electrodes in cells without liquid junction. In order to reduce the correction for "overlapping" of the two acid groups, which are of nearly equal strengths, the 10 solutions studied contained twice as much succinic acid as acid succinate ion. The residual correction of about 0.02 in $\log K_{1}$ was made with the aid of values of the second dissociation constant from an earlier determination.
\end{abstract}

The first dissociation constant between $0^{\circ}$ and $50^{\circ}$ can be expressed by

$$
-\log K_{1}=1206.25 / T-3.3266+1.011697 T,
$$

where $T$ is the absolute temperature, The changes of free energy, heat content, entropy, and heat capacity for the first dissociation step of succinic acid in the standard state were calculated from the dissociation constant and its temperature coefficient.

\section{Introduction}

A determination of the second dissociation constant of succinic acid from $0^{\circ}$ to $50^{\circ}$ was recently reported by the authors [1]. ${ }^{1}$ The two acid groups of this dicarboxylic acid are of nearly equal strengths, and there is considerable overlapping, or simultaneous dissociation. Hence, it was necessary to estimate the first dissociation constant, $K_{1}$, in order to compute the ionic concentrations required for an accurate determination of the second dissociation constant, $K_{2}$. Values of $K_{1}$ were therefore calculated from electromotive-force measurements of solutions of sodium acid succinate with added sodium chloride

1 Figures in brackets indicate the literature references at the end of this paper. from $0^{\circ}$ to $50^{\circ}$ by means of a determination of the product of the two constants [2].

Although adequate for correcting the determination of $K_{2}$, these values of $\log K_{1}$ were estimated to have an uncertainty of \pm 0.01 . Hence, it is doubtful if the earlier results for $K_{1}$ are of sufficient accuracy to warrant the calculation of the heat-content and entropy changes that are of considerable theoretical interest. It seemed desirable to undertake an accurate redetermination of the first dissociation constant in order to obtain reliable information concerning the thermodynamic quantities associated with the first dissociation step.

Ten mixtures of hydrochloric acid and sodium acid succinate were prepared, each containing the 